\title{
Pitfalls of Forward-Looking Monetary Policy
}

\author{
By Michael Woodford*
}

A distinctive feature of the procedures recently adopted by inflation-targeting central banks is their forward-looking character. Forecasts of the economy's future evolution conditional upon alternative policies play a central role in the banks' deliberations, to an extent that the procedures adopted are sometimes characterized as "forecast targeting." This emphasis upon the future consequences of policy is unsurprising in an approach that tries to maintain as transparent as possible a relation between the banks' decisions and the ultimate goals of monetary policy; after all, current decisions can still affect the future, but not the past.

Nonetheless, common descriptions of how inflation targeting is or should be practiced go too far, in proposing purely forward-looking procedures. I shall argue instead that an optimal framework for the conduct of monetary policy must generally be history-dependent in ways precluded by these simple proposals. This follows from a general feature of the optimal control of a forward-looking system, which is to say, one in which the private sector's expectations about future policy are an important determinant of the effects of monetary policy.

\section{Purely Forward-Looking Procedures}

By a purely forward-looking decision procedure for monetary policy I mean one in which the bank's action at any time is conditioned solely upon those aspects of the state of the world that are relevant for forecasting the subsequent evolution of the bank's target variables, which I shall here suppose to be the inflation rate and the level of aggregate economic activity. Examples of such proposals are commonplace in the literature on inflation targeting. For example, Mervyn King (1997) describes infla-

\footnotetext{
* Department of Economics, Princeton University, Princeton, NJ 08544. I thank Julio Rotemberg and Lars Svensson for many helpful discussions, and the NSF for research support.
}

tion targeting as a regime of discretionary policy-making, in which the central bank is charged with minimization of a loss function that differs from the true social objective, in order to eliminate the Kydland-Prescott inflation bias resulting from discretion. King's modified loss function changes only the (constant) target values for the target variables, and not the variables themselves that the bank seeks to stabilize; hence, a Markov equilibrium resulting from discretionary optimization implies a policy that depends only upon states relevant to the determination of current or future inflation and output.

Common descriptions of "inflation-forecast targeting" (e.g., Lars E. O. Svensson, 1999) illustrate this feature even more clearly. Under such procedures, an economic model is used to generate conditional forecast paths for the target variables from the present onward associated with alternative feasible policies. The bank then chooses among the candidate forecast paths, either evaluating them according to a loss function or selecting the path that satisfies some targeting criterion, such as a requirement that the forecast of inflation at some future horizon equals a target value, which may depend upon the output forecast. The bank's current action is then the one required by the chosen scenario. The procedure is repeated afresh in each decision cycle. Past states obviously cannot affect the action that is chosen, if they affect neither the set of scenarios judged to be possible nor the criterion used to choose among alternative scenarios.

Other authors have described inflationtargeting policies as rules for setting a shortterm interest rate as a function of forecasts of the future paths of the target variables (raising interest rates in proportion to the forecasted excess of inflation over the target level). Sometimes the forecast is assumed to correspond to a scenario in which the interest rate is left at its current level; in other cases it represents a forecast of what should happen if the prescribed policy rule is followed. In either case, if the prescribed interest rate is a function only 
of the forecasts, such a decision procedure is purely forward-looking.

\section{Why Optimal Policy Must Be History-Dependent}

It might seem that the property just identified is a simple consequence of optimization, and thus wholly desirable. In particular, one might suppose that, in the case of a social objective that is additively separable over time, familiar principles of dynamic programming imply that optimal policy at any point in time should depend only upon state variables that determine constraints upon possible paths of the target variables from that time onward. However, such principles apply only to the control of a system in which the target variables evolve according to laws of motion that are purely backwardlooking. When, instead, private-sector expectations of the economy's future path are among the determinants of the current values of target variables (as in almost any model of the monetary transmission mechanism derived from optimizing behavior), such a conclusion is incorrect (Woodford, 1999a).

The reason is simple. In general, forwardlooking behavior implies that more desirable responses of the target variables (inflation and output) to a shock can be achieved if it can be arranged for private-sector expectations about the future paths of the target variables to adjust in the right way in response to the shock. However, this can occur (when the private sector has rational expectations) only if subsequent central-bank policy does in fact change as a result of the past shocks in such a way as to bring about the alternative evolution that it was desired that people would expect. However, anticipation by the private sector that the central bank will apply a purely forward-looking procedure at later dates precludes such adjustment of expectations at the earlier date.

The history-dependence of optimal policy can be usefully illustrated in the context of a simple optimizing model of the monetary transmission mechanism, analyzed by Richard Clarida et al. (1999) and by Woodford (1999a), among others. In this model, inflation $\pi_{t}$ and the output gap $x_{t}$ (output relative to its efficient level) are determined by a pair of structural relations, consisting of an aggregate supply curve and an intertemporal
Euler equation. The first relation determines $\pi_{t}$ given $x_{t}$, inflation expectations $\left(E_{t} \pi_{t+1}\right)$, and an exogenous cost shock $u_{t}$. The second determines $x_{t}$ given $E_{t} x_{t+1}$, the expected real rate of return (determined by the central bank's instrument $i_{t}$ and by $\left.E_{t} \pi_{t+1}\right)$, and exogenous variation in the Wicksellian "natural rate of interest" $r_{t}^{\mathrm{n}}$. I assume that social welfare requires the minimization of the expected value of a discounted sum of period losses of the form

$$
L_{t}=\pi_{t}^{2}+\lambda_{x} x_{t}^{2}+\lambda_{i} i_{t}^{2}
$$

for some weights $\lambda_{x}>0, \lambda_{i} \geq 0$.

In this simple model, conditional forecasts in period $t$ of the paths of the target variables from that period onward depend only upon the exogenous state vector $\mathbf{s}_{t}$, describing information at $t$ about the current and future values of the exogenous disturbances $u_{t+j}, r_{t+j}^{\mathrm{n}}$. Thus any determinate equilibrium resulting from a purely forward-looking procedure makes $i_{t}, \pi_{t}$, and $x_{t}$ functions solely of $\mathbf{s}_{t}$. If the disturbances are Markovian, this means a function only of the current disturbances $u_{t}$ and $r_{t}^{\mathrm{n}}$.

Except in the special case that $\lambda_{i}=0$ and there are no cost shocks, an optimal equilibrium requires these variables to be functions of lagged disturbances as well. For example, in the case of a transitory cost shock, a forwardlooking procedure results in an equally transitory increase in inflation and decrease in output, with both variables expected to return to their average values once the disturbance is past. However, an optimal commitment would involve a negative output gap that returns to zero only slowly, so that the initial burst of inflation is expected to be followed by a period of disinflation; when $\lambda_{i}=0$, this eventually returns the price level to its original trend path (Clarida et al. 1999; Woodford, 1999b). This expectation of subsequent disinflation mitigates the effects of the adverse cost shock, by restraining price increases during the period of the shock.

Similarly, in the case of a transitory increase in the natural rate of interest, a forward-looking procedure results in an equally transitory increase in the nominal interest rate. When $\lambda_{i}>0$, an optimal commitment instead involves a more persistent increase in the nominal interest rate (Woodford, 1999a). This results in a larger response of long rates (which restrain 
expenditure and hence prices despite the disturbance), without requiring a sharp increase in short rates. As a result, it is possible to simultaneously achieve lower volatility of inflation, the output gap, and the short-term nominal interest rate.

Purely forward-looking procedures forfeit these gains from desirable responses of inflation expectations and interest-rate expectations to exogenous shocks. In addition, purely forwardlooking approaches more easily result in indeterminacy of equilibrium. In the model sketched above, an exogenously specified nominal interest-rate process results in price-level indeterminacy; a determinate equilibrium requires a sufficient degree of dependence (of the right sort) of the central bank's interest-rate operating target upon endogenous variables, such as inflation and output (Woodford, 1999a). Furthermore, an operational procedure must make the interest rate a function of variables that are exogenous or predetermined at the time that the interest rate is chosen (Svensson and Woodford, 1999). In the case of a purely forward-looking procedure, this means a function solely of the exogenous state $\mathbf{s}_{t}$, as no predetermined endogenous variables are relevant for forecasting the target variables. But such a procedure necessarily leads to indeterminacy of the paths of both inflation and output.

\section{Examples of History-Dependent Policy}

There are a variety of ways in which a decision procedure for monetary policy might incorporate the sort of history-dependence required for an optimal regime. As Svensson and Woodford (1999) stress, these include history-dependent variants of inflation-forecast targeting procedures. For example, a forecasttargeting procedure that amounts to discretionary optimization can nonetheless be sufficiently history-dependent, if the loss function that the central bank seeks to minimize is modified in a way that introduces history-dependence.

A particularly straightforward approach is to incorporate into the bank's loss function terms that represent the value, at earlier dates, of having people anticipate different subsequent paths of the target variables (Svensson and Woodford, 1999). For example, in the simple model above, one might instead direct the central bank in period $t$ to seek to minimize an objective that adds terms of the form $\phi_{1, t-1} \pi_{t}+\phi_{2, t-1} x_{t}$ to the expected discounted sum of terms $L_{t+j}$ for $j \geq 0$. Here the coefficients $\phi_{i, t-1}$ are determined as part of the bank's period- $t-1$ decision cycle and then taken as given parameters of the bank's objective in its period- $t$ decision cycle. A discretionary procedure of this kind has a Markov equilibrium in which inflation and output evolve as under the optimal commitment, and the coefficients $\phi_{i, t-1}$ are set equal to Lagrange multipliers associated with that optimization problem.

This approach represents a relatively general solution to the problem of making optimal policy consistent with a discretionary optimization procedure. However, the practicality of the proposal may be doubted. Since the coefficients $\phi_{i, t-1}$ result from the central bank's calculations when choosing period- $t-1$ policy, they respond to no endogenous variables (not chosen by the bank itself) determined in period $t-1$ and so will be a function solely of the history of exogenous disturbances. Such a procedure once again implies an interest-rate reaction function that leads to indeterminacy (Svensson and Woodford, 1999).

On both grounds one might therefore prefer an alternative approach, in which the modified loss function involves no time-varying coefficients, but instead a period loss function that depends upon lagged as well as current values of the target variables. In this case, discretionary policy is history-dependent because the bank's loss function is history-dependent (even though the true social loss function is not). The implied reaction function will make the nominal interest rate a function of lagged endogenous variables-dependence of which sort is necessary, though not sufficient, for determinacy of equilibrium.

For example, David Vestin (1999) shows that discretionary optimization results in more nearly optimal responses to cost shocks (in the above model, with $\lambda_{i}=0$ ) if the central bank is charged with stabilization of the price level rather than the inflation rate, even though the true social loss function is that shown in equation (1). The proposed loss function is history-dependent, in that it effectively depends upon the cumulative sum of inflation rates over all past periods, rather than only upon the current period's inflation rate. This 
is desirable, as it implies that an inflationary shock should cause anticipation of lower inflation in subsequent periods, to an extent that the price level is expected to eventually return to its original level.

Similarly, Henrik Jensen (1999) shows that a nominal GDP growth target can be preferable to discretionary minimization of the true social loss function ("inflation targeting") in a similar model. This makes the period loss function depend upon lagged output as well as the current values of target variables. Specifically, low output in the previous period leads the central bank to choose low output and/or deflation in the current period. As a result, a transitory cost shock results in a more persistent contraction of output, lowering overall inflation and output variability as discussed above.

Finally, Woodford (1999a) shows that more nearly optimal equilibrium responses to fluctuations in the natural rate of interest (in the model with $\lambda_{i}>0$ ) result from discretionary optimization if the central bank's period loss function is given by

$$
L_{t}^{\mathrm{cb}}=\pi_{t}^{2}+\lambda_{x} x_{t}^{2}+\lambda_{\Delta}\left(i_{t}-i_{t-1}\right)^{2}
$$

for an appropriate choice of $\lambda_{\Delta}>0$, rather than by the true social loss function (1). Such an "interest-rate smoothing" objective induces the sort of gradual adjustment of the interest rate that characterizes responses under the optimal commitment.

The appeal of such modified central-bank objectives depends, of course, upon the expectation that a discretionary optimizer will not efficiently achieve its official aims. An appealing alternative involves commitment to the achievement of a specific targeting criterion. Introducing history-dependence is especially straightforward under such an approach; one simply needs a targeting criterion that depends upon past values of the target variables, as well as their current and future values.

For example, in the case that $\lambda_{i}=0$, Woodford (1999a) shows that a policy that ensures that inflation satisfies the targeting criterion

$$
\pi_{t}+\left(\lambda_{x} / \kappa\right)\left[x_{t}-x_{t-1}\right]=0
$$

(where $\kappa$ is the slope of the short-run Phillips curve) suffices to ensure that the equilibrium responses to cost shocks are optimal. The targeting criterion is history-dependent in that (3) involves $x_{t-1}$. Note that if the efficient level of output is a deterministic trend, and $\lambda=\kappa$, this rule corresponds to nominal GDP-growth targeting, as proposed by Jensen; however, the latter rule is fully optimal only in this special case.

In the more general case that $\lambda_{i}>0$, Marc P. Giannoni (1999) shows that the optimal targeting criterion instead takes the form

$$
\begin{aligned}
i_{t}= & \rho_{1} i_{t-1}+\rho_{2}\left(i_{t-1}-i_{t-2}\right) \\
& +\psi_{\pi} \pi_{t}+\psi_{x}\left(x_{t}-x_{t-1}\right)
\end{aligned}
$$

for appropriately chosen coefficients $\rho_{1}, \rho_{2}, \psi_{\pi}$, $\psi_{x}>0$. The optimal values of these coefficients depend upon the coefficients of the structural equations and of the loss function (4), but they are completely independent of all parameters specifying the shock processes. Again this condition determines a unique nonexplosive equilibrium corresponding to the optimal commitment.

The targeting criterion (4) provides a rule for setting the central bank's interest-rate instrument that is in the spirit of the "Taylor rule." But it differs from John B. Taylor's (1993) classic formulation in involving additional history-dependence: interest rates respond to the growth rate of the output gap rather than to its level, and the coefficients $\rho_{1}, \rho_{2}>0$ imply inertial interest-rate dynamics. It is interesting to note that both of these departures from Taylor's formulation characterize at least some econometric estimates of actual Fed reaction functions (e.g., John P. Judd and Glenn D. Rudebusch, 1998).

This example indicates that an optimal targeting criterion need not involve forecasts for periods beyond the one for which interest rates are being set. In this case, private-sector anticipation of subsequent central-bank action substitutes for preemptive actions by the central bank. However, the optimality of this rule under an arbitrary information structure depends upon the absence of intrinsic dynamics in the model's structural equations; more generally, an optimal targeting criterion will 
involve forecasts, as in Svensson (1999). Even so, an optimal procedure will not generally be purely forward-looking, but will instead have to involve backward-looking elements of the kind illustrated here.

\section{REFERENCES}

-Clarida, Richard; Galí, Jordi and Gertler, Mark. "The Science of Monetary Policy: A New Keynesian Perspective." Journal of Economic Literature, December 1999, 37(4), pp. 1661-1707.

Giannoni, Marc P. "Does Model Uncertainty Imply Caution? Robust Optimal Monetary Policy in a Forward-Looking Model." Mimeo, Princeton University, 1999.

Jensen, Henrik. "Targeting Nominal Income Growth or Inflation?" Mimeo, University of Copenhagen, 1999.

Judd, John P. and Rudebusch, Glenn D. "Taylor's Rule and the Fed: 1970-1997." Economic Review (Federal Reserve Bank of San Francisco), 1998, (3), pp. 3-16.

-King, Mervyn. "Changes in UK Monetary Policy: Rules and Discretion in Practice." Jour- nal of Monetary Economics, June 1997, 39(1), pp. 81-97.

-Svensson, Lars E. O. "Inflation Targeting as a Monetary Policy Rule." Journal of Monetary Economics, June 1999, 43(3), pp. 60754.

Svensson, Lars E. O. and Woodford, Michael. "Implementing Optimal Policy Through Inflation-Forecast Targeting." Mimeo, Princeton University, 1999.

- Taylor, John B. "Discretion versus Policy Rules in Practice." Carnegie-Rochester Conference Series on Public Policy, December 1993, 39. pp. 195-214.

Vestin, David. "Price-Level Targeting versus Inflation Targeting in a Forward-Looking Model." Mimeo, Stockholm University, 1999.

Woodford, Michael. "Optimal Monetary Policy Inertia." National Bureau of Economic Research (Cambridge, MA) Working Paper No. 7261, August 1999a.

- "Commentary: How Should Monetary

Policy Be Conducted in an Era of Price Stability?" in New challenges for monetary policy. Kansas City, MO: Federal Reserve Bank of Kansas City, 1999b. 


\section{This article has been cited by:}

1. Michał Brzoza-Brzezina, Jacek Kotłowski, Agata Miśkowiec. 2013. How forward-looking are central banks? Some evidence from their forecasts. Applied Economics Letters 20:2, 142-146. [CrossRef]

2. Aaron Mehrotra, José R Sánchez-Fung. 2010. China's Monetary Policy and the Exchange Rate. Comparative Economic Studies 52:4, 497-514. [CrossRef]

3. CHRISTIAN JENSEN, BENNETT T. MCCALLUM. 2010. Optimal Continuation versus the Timeless Perspective in Monetary Policy. Journal of Money, Credit and Banking 42:6, 1093-1107. [CrossRef]

4. MICHELE BERARDI. 2009. Monetary Policy with Heterogeneous and Misspecified Expectations. Journal of Money, Credit and Banking 41:1, 79-100. [CrossRef]

5. HEINZ-PETER SPAHN. 2007. EXCHANGE RATE STABILISATION, LEARNING AND THE TAYLOR PRINCIPLE. Australian Economic Papers 46:2, 136-151. [CrossRef]

6. Q. Farooq Akram, Gunnar Bärdsen, Øyvind Eitrheim. 2006. Monetary policy and asset prices: to respond or not?. International Journal of Finance \& Economics 11:3, 279-292. [CrossRef]

7. Alessandro Piergallini. 2005. Equilibrium Determinacy under Monetary and Fiscal Policies in an Overlapping Generations Model. Economic Notes 34:3, 313-330. [CrossRef]

8. Ulf Soderstrom. 2005. Targeting Inflation with a Role for Money. Economica 72:288, 577-596. [CrossRef]

9. Otmar Issing. 2004. Geldpolitik fur den Euroraum. Perspektiven der Wirtschaftspolitik 5:4, 381-404. [CrossRef]

10. Gunnar Bårdsen, Eilev S. Jansen, Ragnar Nymoen. 2003. Econometric inflation targeting. Econometrics Journal 6:2, 430-461. [CrossRef]

11. Michael Woodford. 2003. Optimal Interest-Rate Smoothing. Review of Economic Studies 70:4, 861-886. [CrossRef]

12. Lars E. O. Svensson. 2003. What Is Wrong with Taylor Rules? Using Judgment in Monetary Policy through Targeting Rules. Journal of Economic Literature 41:2, 426-477. [Abstract] [View PDF article] [PDF with links] 